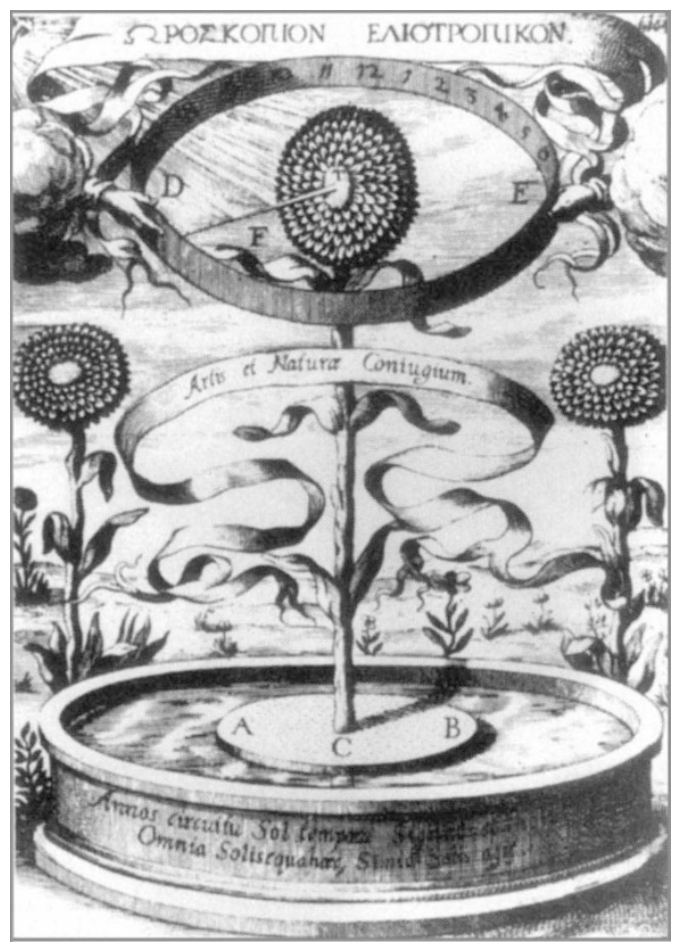

Blooming marvellous: Kircher's sunflower clock.

effort towards a mechanical description of nature. According to Hankins and Silverman, even if one assumes that Helmholtz shared Vaucanson's goal, there remains an obvious qualitative difference between the mechanical duck and Helmholtz's tuning-fork synthesizer. Vaucanson's duck copied animal functions as they were observed (from the outside); Helmholtz's apparatus copied what he thought to be the mechanism of sound. From our perspective, Helmholtz's approach is the more scientific. A modern comparison perhaps is between the old way of creating a flavour by mixing chemicals and the modern way by copying the molecule responsible for that flavour.

Athanasius Kircher's sunflower clock which purported to tell the time through a cosmic magnetic force teaches us the same lesson. By our standards the clock was a fraud but definitely not by his. No-one can deny that there is an ocean of difference between the sunflower clock and the microscope or the air pump, but in a real sense all three were emblems of their time: the sunflower clock of early-seventeenth-century natural magic, the microscope of the new generation of senseexpanding instruments of midseventeenth-century natural philosophy and the air pump of the new generation of laboratory devices of experimental philosophy that allowed active exploration of natural phenomena in the laboratory.

Hankins and Silverman ask the important question whether the inability of Helmholtz's generation to understand Vaucanson's duck (and by the same token Kircher's sunflower clock) was caused by a shift in the boundaries of acceptable sci- ence, or by a completely different concept of what science should be. The fact that the question can be asked suggests that the criteria for what counts as 'scientific' have never been fixed. That is the core message of their book.

Catherine Wilson's treatise on the impact of the microscope on seventeenthcentury thought covers very much the same ground. Her key years are the period from 1620 to about 1720 , by which time the main arguments about the validity of observations made with this device had been resolved.

Microscopists had to deal with such knotty issues as the relative status of fact and observation; and the historian evaluating their work must decide whether seventeenth-century 'proto-science' was an immature form of modern science or something else altogether - a similar problem to that faced by Hankins and Silverman over Helmholtz. Wilson shows that microscopic observations reinforced the contemporary idea of the 'living machine' - that is, a reductionist view of nature. And therein lies the ultimate paradox of our machinedriven science, which is highlighted by both books: the essence of our natural world remains hidden despite our increasingly sophisticated scientific technology. Perhaps The Invisible World is better off with no pictures after all.

Willem Hackmann is at the Museum of the History of Science, University of Oxford, Broad Street, Oxford OX1 3AZ, UK.

\title{
Underground art
}

ON 18 December 1994, three cavers in the Ardèche, southeast France, stumbled across more than 300 wall paintings dating back 30,000 years in a hidden underground cavern - the world's oldest examples of prehistoric art and some 15,000 years older than the renowned paintings at Lascaux. Chauvet cave is startling in many respects: it is completely intact, showing varied traces of prehistoric human and animal visitors, including the already notorious bear skull placed on a rock, which has led to much untrammelled speculation about bear cults; and it is decorated with images of many different species rhinoceroses, big cats and bears - previously unknown in the region's Ice Age art, but also rare elsewhere, and certainly not usually depicted with such prominence. For example, fewer than 20 rhinos were previously known in European cave art, whereas Chauvet contains between two to three times that many alone. The images are particularly impressive for the techniques used to present perspective and motion: many figures interact, some are staggered and others are drawn on bulges in the cave walls to suggest depth. Unlike Lascaux, this cave is now closed to the public and its priceless heritage has been seen by only a privileged few. In Chauvet Cave, Jean-Marie Chauvet, Eliette Brunel Deschamps and Christian Hillaire now recount the tale of their discovery and present colour photographs of the remarkably sophisticated paintings, which are analysed and set in context by the prehistoric art specialists Paul Bahn and Jean Clottes. Thames and Hudson, $£ 28$.

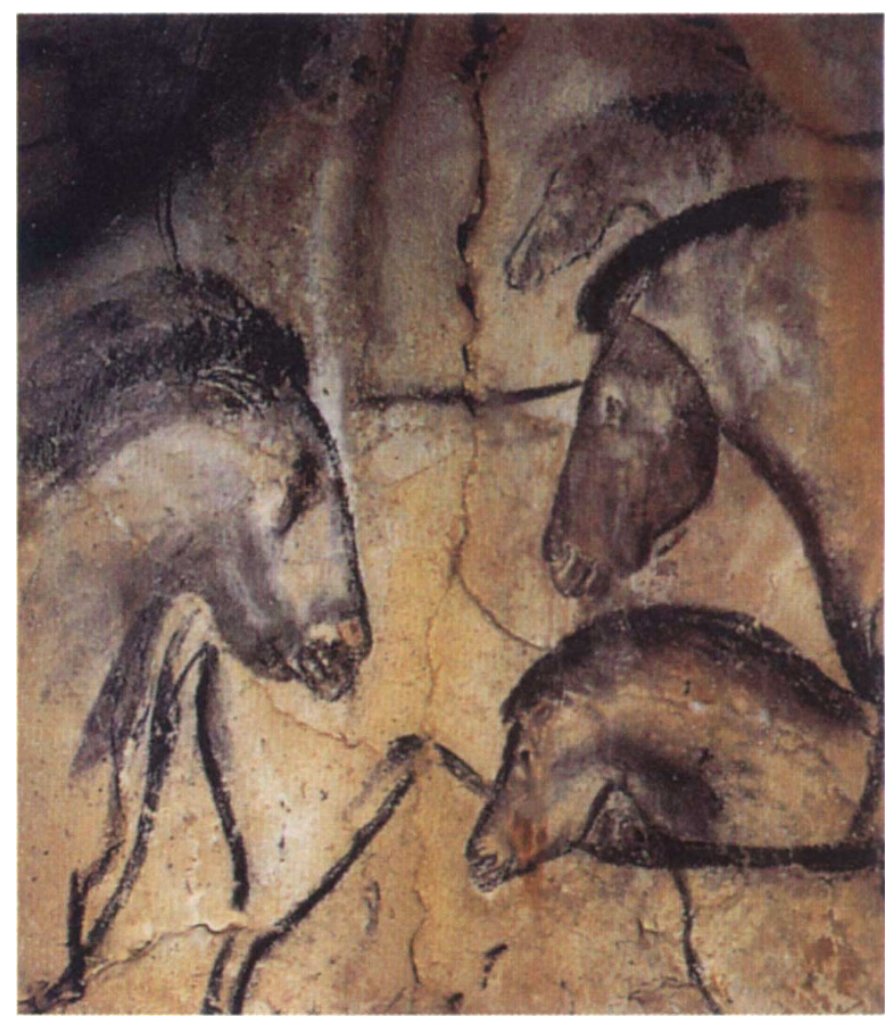

